\title{
Investigation of Perfluoroalkyl Substances (PFASs) in Sediments from the Urban Lakes of Anqing City, Anhui Province, China
}

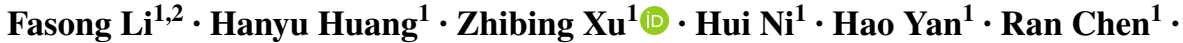 \\ Yan Luo $^{3} \cdot$ Wei Pan ${ }^{1} \cdot$ Jinyun Long $^{1} \cdot$ Xiaofang Ye $^{1} \cdot$ Xiaofen Qian $^{1} \cdot$ Guangming Yu$^{1}$
}

Received: 17 August 2017 / Accepted: 3 November 2017 / Published online: 8 November 2017

(C) Springer Science+Business Media, LLC, part of Springer Nature 2017

\begin{abstract}
Fifteen individual perfluoroalkyl substances (PFASs) were analyzed in 22 sediment samples collected from Anqing urban lakes (Anhui province, China) by ultraperformance liquid chromatography-tandem mass spectrometry (UPLC-MS/MS). Total PFAS concentration was between 0.61 and $26 \mathrm{ng} \mathrm{g}^{-1}$ dry weight. Perfluorooctane sulfonate (PFOS) was the dominant PFAS contaminant, with a concentration range of $<0.040-13 \mathrm{ng} \mathrm{g}^{-1}$. Results indicated higher total PFAS concentrations in lakes located to the northwest of Anqing City than in other regions. Adjacent chemical and industrial factories were hypothesized to be responsible for these higher PFAS levels in those lakes. In comparison to other measurements obtained from other lakes, PFAS concentrations in the urban lakes of Anqing City were relatively high.
\end{abstract}

Keywords Perfluorinated compounds $\cdot$ Sediment $\cdot$ Urban lakes Anqing City

Perfluoroalkyl substances (PFASs) have been used for over 60 years across many industries, including as surface protectors for paper as well as in carpets, floor polishes, food containers, and fire-fighting foams (Prevedouros et al. 2006;

Zhibing Xu

2445115274@qq.com

1 College of Environmental Resources, Anqing Normal University, Anqing 246011, China

2 State Key Laboratory of Environmental Chemistry and Ecotoxicology, Research Center for Eco-Environmental Sciences, Chinese Academy of Sciences, Beijing 100085, China

3 Department of Chemical Engineering, West Virginia University, Morgantown, WV 26506, USA
Kissa 2001; Hou et al. 2015). A component part to PFASs is their strong $\mathrm{C}-\mathrm{F}$ bond, which is stable and resistant to both chemical and biological degradation. As such, PFASs were widely distributed in the environment and have remained there (Lindstrom et al. 2011; Li et al. 2011; Zhou et al. 2013; Ding et al. 2017; Liu et al. 2017). Perfluorooctanoic acid (PFOA) and perfluorooctane sulfonate (PFOS) are two representative PFASs that are known to have toxic, bioaccumulative effects (Lindstrom et al. 2011). To this end, the United Nations Environment Program (UNEP) recently listed PFOS and perfluorooctanesulfonyl fluoride (PFOSF) as persistent organic pollutants (POPs) during the Stockholm Convention in 2009 (UNEP 2009).

Although a variety of PFAS-containing products have been restricted in their manufacture and use since 2000 (e.g. 3M, Phase-Out Plan for POSF Based Products 2000), PFAS-containing products are still widely used. This is due to their unique physical-chemical properties-environmental considerations notwithstanding (Lau et al. 2007). Globally, PFASs have been found in a variety of environmental samples (Yamashita et al. 2008), but aquatic environments appear to be their preferred medium-particularly in sediment (Li et al. 2011; Pan et al. 2014). Due to their hydrophobic interaction, sediments in aqueous environments act as a sink for adsorbing PFASs, especially perfluoroalkyls sulfonates and long-chain ( $>$ C8) perfluorinated carboxylic acids (PFCAs) (Li et al. 2011; Ahrens et al. 2009).

In China, PFASs have been detected in many aqueous environments, including the Yangtze River, Pearl River, Liao River, Haihe River, and Hun River as well as Baiyangdian Lake. They have even been found in the coastal waters around China (So et al. 2007; Sun et al. 2011; Li et al. 2011; Shi et al. 2012; Hou et al. 2012, 2013). Anqing City is located in the middle and downstream areas of the Yangtze River and is an important chemical industrial base. 
Many of the enterprises and plants in the city are associated with the chemical or petrochemical industries. In addition, numerous lakes are located in urban districts, such as Lin Lake, Lianhu Lake, Dongda Lake, and Xixiao Lake (Han et al. 2017). These urban lakes are either directly polluted by industrial and domestic wastewaters or indirect due to rainwater contamination (Han et al. 2017). Previous studies on Anqing urban lakes were mostly focused on heavy metals, chemical oxygen demand, total phosphorus, and other routine water-quality parameters (Han et al. 2017). However, PFAS contamination in this region has not been reported. Here, the contamination characteristics and spatial distribution of PFASs in sediments from Anqing urban lakes were determined. We also provide additional discussion regarding the sources of the PFASs. This work will provide basic data and scientific support for future PFAS contaminative control and risk assessment in Anqing City.

\section{Materials and Methods}

Twenty-two sites from six urban lakes, including Dongda Lake (D1-D7, Fig. 1), Xixiao Lake (X1-X4, Fig. 1), Lin Lake (L1-L6, Fig. 1), Lianhu Lake (LH1-LH3, Fig. 1), Shuishang Park (S1, Fig. 1), and Shengtang Lake (ST1, Fig. 1) were sampled in April 2015. All site locations were mapped and shown in Fig. 1. Sediment samples were collected near the surface $(0-10 \mathrm{~cm})$ using a stainless-steel grab sampler. Samples were then individually stored in polypropylene (PP) zip-lock bags. Sediments were kept at $0^{\circ} \mathrm{C}$ and then dried in a freeze-drier. All sediment sampling vessels were sequentially washed using Milli-Q water, methanol, and the specific site's water before sampling. Teflon laboratory materials were not used to avoid possible PFAS contamination.

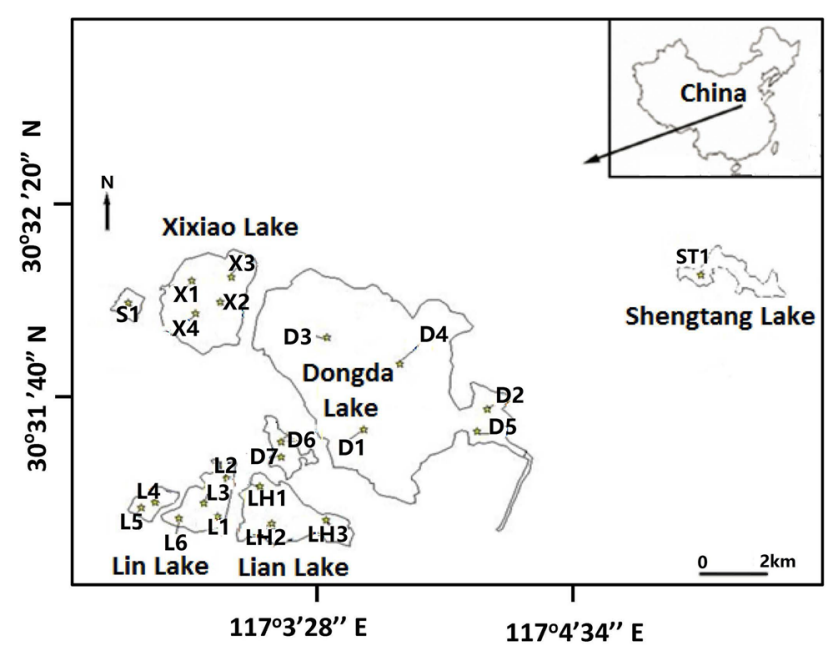

Fig. 1 Sampling locations in Anqing urban lakes from Anhui province, China
PFOS (99\% purity), perfluorohexanoic sulfonate (PFHxS, 98\% purity), perfluorobutanoic sulfonate (PFBS, 98\% purity), perfluorododecanoic acid (PFDoA, 95\% purity), and perfluorobutanoic acid (PFBA, 98\% purity) were all obtained from Sigma-Aldrich Chemical USA, Ltd. (St Louis, MO, USA). Perfluoroundecanoic acid (PFUnA, $>96 \%$ purity), perfluoroheptanoic acid (PFHpA, >98\% purity), perfluorohexanoic acid (PFHxA, > 98\% purity), and perfluoropentanoic acid (PFPeA, 98\% purity) were all obtained from Matrix Scientific USA, Ltd. (Columbia, SC, USA). PFOA (>98\%) was purchased from Strem Chemicals (Bischheim, France). Perfluorodecanoic acid (PFDA, $>98 \%$ purity) and perfluorononanoic acid (PFNA, $>98 \%$ purity) were purchased from Fluorochem (Derbyshire, UK). ${ }^{13} \mathrm{C}_{4}$-Labeled sodium PFOS $\left({ }^{13} \mathrm{C}_{4}\right.$-PFOS $), 6: 2$ fluorotelomer unsaturated acid (6:2 FTUCA), 8:2 fluorotelomer unsaturated acid (8:2 FTUCA), ${ }^{13} \mathrm{C}_{2}-8: 2$ FTUCA, and N-Methyl-heptadecafluorooctane sulfonamide (N-Me-FOSA, $>98 \%$ purity) were obtained from Wellington Laboratories (Ontario, Canada). ${ }^{13} \mathrm{C}_{8}$-Labeled PFOA $\left({ }^{13} \mathrm{C}_{8}\right.$-PFOA) was obtained from Cambridge Isotope Laboratories (MA, USA). Waters Oasis WAX (150 mg, $6 \mathrm{cc}$ ) solid-phase extraction cartridges were purchased from the Waters Corporation. Methanol (HPLC grade) was purchased from Dikma Technologies USA Ltd. (Lake Forest, CA, USA). Finally, Mill-Q water was obtained using a Milli-Q Advantage system.

Sediment samples were prepared according to our previously published method (Li et al. 2011). Briefly, $0.5 \mathrm{~g}$ dried sediment was first weighted into $15 \mathrm{~mL}$ PP tube, and internal standards $(5 \mathrm{ng})$ and Milli-Q water $(0.5 \mathrm{~mL})$ were spiked into the sediment. Then the spiked sediment was extracted with methanol for three times $(2.5,1.5$, and $1.0 \mathrm{~mL})$. Each extraction was shaked for $10 \mathrm{~min}$, sonicated for $20 \mathrm{~min}$, and centrifuged at $3500 \mathrm{rpm}$ for $8 \mathrm{~min}$ sequentially. Finally the purification processes of extracts were performed by adding Envicarb particles $(150 \mathrm{mg}$ ) and shaking for $15 \mathrm{~min}$, and separating by centrifuging at $3500 \mathrm{rpm}$ for $10 \mathrm{~min}$. And then the volume was adjusted to $0.5 \mathrm{~mL}$ exactly under gentle nitrogen gas.

Resulting extracts were analyzed using Waters Acquity ultra-performance liquid chromatography (UPLC-MS/MS) equipped with Waters Acquity TQD triple quadrupole mass spectrometer (Waters, USA). MS/MS was conducted in electrospray negative ionization and using a multiple reaction monitoring (MRM) mode. A small (approximately $5 \mu \mathrm{L}$ ) aliquot of the extract was injected into an ACQUITY UPLC BEH C18 column $(2.1 \mathrm{~mm}$ id. $\times 50 \mathrm{~mm})$. The mobile phases were methanol (A) and $2 \mathrm{mM}$ ammonium acetate in Milli-Q water (B). The flow rate was $0.40 \mathrm{~mL} \mathrm{~min}{ }^{-1}$. The gradient elution began at $25 \% \mathrm{~A}$ for the initial $0.5 \mathrm{~min}$, was increased to $85 \% \mathrm{~A}$ at $5 \mathrm{~min}$, increased to $100 \%$ in $0.1 \mathrm{~min}$ for $1.9 \mathrm{~min}$, and then reverted to $25 \% \mathrm{~A}$ at $9 \mathrm{~min}$. The parameters were as follows: Source temperature of $150^{\circ} \mathrm{C}$, capillary voltage 
at $-2.7 \mathrm{kV}$ for all target compounds, desolvation gas flow at $700 \mathrm{~L} \mathrm{~h}^{-1}$, desolvation temperature at $350^{\circ} \mathrm{C}$, cone gas flow at $20 \mathrm{~L} \mathrm{~h}^{-1}$, and column temperature of $40^{\circ} \mathrm{C}$.

The linearity was evaluated using a seven-point calibration of different concentrations covering a range of $0.1-100 \mu \mathrm{g} \mathrm{L}^{-1}$ with ${ }^{13} \mathrm{C}-8: 2$ FTUCA, ${ }^{13} \mathrm{C}-\mathrm{PFOA}$, and ${ }^{13} \mathrm{C}$-PFOS as internal standards. The calibration curve indicated strong linearity with a correlation coefficient greater than 0.99 ( $r>0.99)$.

Recalibration using procedural blanks $(0.5 \mathrm{~g}$ quartz sand for sediment) was conducted every 10 sediment samples to check for background and carryover contamination. Target PFASs were not analyzed in every blank. The travel blank also did not detect any extra PFAS contamination. The limit of quantitation (LOQ) ranged from 0.02 to $0.10 \mathrm{ng} \mathrm{g}^{-1}$ for each sediment sample.

Matrix spikes were achieved by spiking PFAS standard (5.0 ng each) with $0.5 \mathrm{~g}$ selected sediment samples $(\mathrm{n}=3)$. The recoveries of the matrix spikes were in the range of $88 \%-102 \%$, with a standard deviation (SD) of no greater than $5.5 \%$. Finally, duplicate samples were run separately, with less than $12 \%$ relative standard deviations (RSD) between them.

\section{Results and Discussion}

The total concentration for the 15 PFASs in the tested sediment samples obtained from urban lakes of Anqing City ranged from 0.61 to $26 \mathrm{ng} \mathrm{g}^{-1}$ dry weight. The average concentration was $9.1 \mathrm{ng} \mathrm{g}^{-1}$ (Fig. 2). The highest level was found at Xixiao Lakes (X1-X4), with a concentration range of 15-26 ng g $\mathrm{g}^{-1}$ and an average level of $21 \mathrm{ng} \mathrm{g}^{-1}$. This was followed by Dongda Lake (D1-D7) and Shuishang park

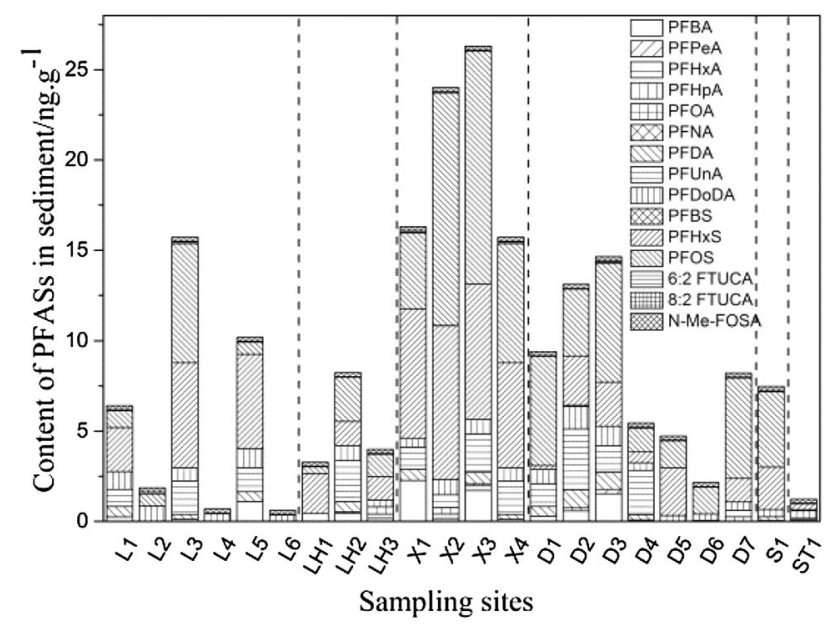

Fig. 2 Composition and spatial distribution of PFASs in sediment of Anqing urban lakes
(S1), with average levels of 8.2 and $7.5 \mathrm{ng} \mathrm{g}^{-1}$, respectively. These three lakes were located in the northwest region of Anqing City, where most of chemical and industrial factories are located, including the famous Anqing Petrochemical Corporation (Han et al. 2017). It is highly likely that these factories are responsible for the higher PFAS levels found in these particular lakes. Total PFAS concentration in Ling Lake (L1-L6) and Lianhu Lake (LH1-LH3) were in the mid-range, with average concentrations of 5.9 and $5.2 \mathrm{ng} \mathrm{g}^{-1}$, respectively. The lowest PFAS levels was $1.2 \mathrm{ng} \mathrm{g}^{-1}$ for Shengtang Lake (ST1), which is located in the northeast of Anqing City and is a newly-built region.

Of the investigated 15 PFASs, only PFNA was undetectable in the tested sediment samples (Fig. 3). PFOS, PFHxS, PFUnA, PFDoDA, PFBA, PFDA, N-Me-FOSA, and 8:2 FTUCA concentrations had LOQ ranges of $<0.040-13,<0.058-8.5,<0.020-3.4,<0.051-1.3$, $<0.10-2.3<0.083-1.0,0.20-0.24$, and $0.034-0.11 \mathrm{ng} \mathrm{g}^{-1}$, respectively. Their average values were 3.6, 2.7, 0.96, 0.63, $0.42,0.30,0.22$, and $0.055 \mathrm{ng} \mathrm{g}^{-1}$, respectively. Given this, the specific average PFAS levels followed the following order. PFOS $>$ PFHxS $>$ PFUnA $>$ PFDoDA $>$ PFBA $>$ PFD A $>$ N-Me-FOSA $>$ 8:2 FTUCA. Other PFAS homologues were at very low average levels $\left(<0.10 \mathrm{ng} \mathrm{g}^{-1}\right)$ and at lo w detection frequencies $(0 \%-23 \%)$. Taken together, these results indicate that perfluoroalkyls sulfonates (PFOS and PFHxS) and long-chain PFCAs (PFUnA, PFDoDA and PFDA) are the dominant PFAS types of the 15 tested PFAS homologues. These findings are in accordance with their higher distribution coefficient between sediment and water (Li et al. 2011).

Additionally, PFBA — a short-chain PFCA — was also detected at high levels and frequencies. In fact, PFBA can act as a substitute for long-chain PFCAs and has been more

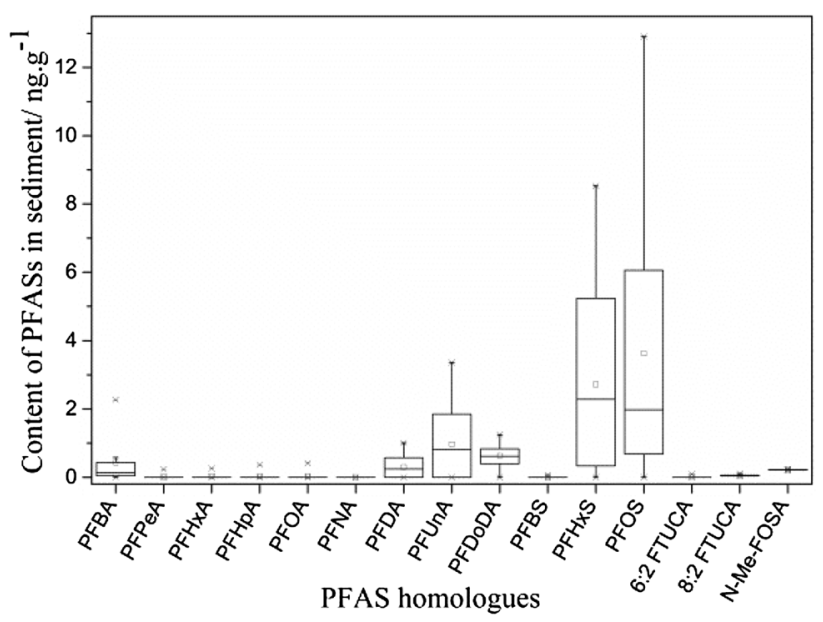

Fig. 3 Concentrations of PFAS homologues in sediment of Anqing urban lakes 
Table 1 Comparison of sediment PFOS/PFOA concentrations from those of other lakes.

\begin{tabular}{|c|c|c|c|}
\hline \multirow[t]{2}{*}{ Location } & \multicolumn{2}{|c|}{ Concentration $\left(\mathrm{ng} \mathrm{g}^{-1}\right)$} & \multirow[t]{2}{*}{ Literatures } \\
\hline & PFOS & PFOA & \\
\hline \multicolumn{4}{|l|}{ China } \\
\hline Anqing urban lakes & $<0.040-13$ & $<0.031-0.42$ & Present study \\
\hline Nansi Lake & $0.17-0.83$ & $0.11-0.44$ & Cao et al. (2015) \\
\hline Baiyangdian Lake & $0.11-0.64$ & n.d-0.30 & Shi et al. (2012) \\
\hline Dianchi Lake & $0.07-0.83$ & n.d-0.71 & Zhang et al. (2012) \\
\hline Taihu Lake & $<0.11-11$ & $4.8-22$ & Pan et al. (2014) \\
\hline Tangxun Lake & $0.48-6.4$ & $11-623$ & Zhou et al. (2013) \\
\hline Hongfeng Lake & $0.07-0.51$ & n.d -0.16 & Liu et al. (2015) \\
\hline Fourteen lakes in Jiangsu Province, & Mean: 0.38 & Mean: 0.32 & Qi et al. (2017) \\
\hline Chaohu Lake & $0.24-0.67$ & $0.12-0.49$ & Qi et al. (2015) \\
\hline \multicolumn{4}{|l|}{ Other countries } \\
\hline Lake Michigan, USA & n.d-1.2 & n.d-0.42 & Codling et al. (2014) \\
\hline Lake Ontario, Canada & $0.68-52$ & $0.079-5.0$ & Yeung et al. (2013) \\
\hline Rivers and lakes, Korea & $0.01-0.48$ & nd- -0.28 & Lam et al. (2014) \\
\hline Lake Superior, USA & n.d & n.d-0.68 & De Silva et al. (2011) \\
\hline Lake Tana, Ethiopia & Mean:0.14 & n.a & Ahrens et al. (2016) \\
\hline
\end{tabular}

$n . d$ not detected, n.a not available widely used and distributed in recent years (Shao et al. 2016, $\mathrm{Su}$ et al. 2017). This may have resulted in the higher levels seen in the sediment samples. As volatile PFAS precursors, 8:2 FTUCA and N-Me-FOSA were evenly distributed and detected at very low levels, but with high frequencies (100\%).

As shown in Table 1, PFOS concentrations in sediments obtained from the urban lakes of Anqing City were comparable to those of Taihu and Tangxun Lakes in China and Lake Michigan in the USA. They were lower than those found in the Canadian side of Lake Ontario and one order of magnitude higher than the other lakes listed in Table 1. PFOA concentrations in the urban lake sediment of Anqing City were 1-3 orders of magnitude lower than those in Tangxun and Taihu Lakes from China and the Canadian side of Lake Ontario, but comparable to the other lakes listed in Table 1.

This study investigated PFAS concentrations in sediment obtained from the urban lakes of Anqing City in China. Total PFAS concentrations were within the range of $0.61-26 \mathrm{ng} \mathrm{g}^{-1}$. Total PFAS concentrations in the sediment obtained from the three lakes located in the northwestern region of Anqing City (Xixiao Lake, DongDa Lake, and Shuishang Park) were higher than those in other regions. It is highly likely that the adjacent chemical and industrial factories are responsible for these higher PFAS levels. PFOS was the dominant PFAS of the fifteen detected PFAS homologues, with a range of $<0.040-13 \mathrm{ng} \mathrm{g}^{-1}$. PFOA was detected at low levels with a range of $<0.031-0.42 \mathrm{ng} \mathrm{g}^{-1}$. Perfluoroalkyls sulfonates and long-chain PFCAs were detected at relatively higher levels and frequencies, which may be due to their higher distribution coefficient between sediment and water. PFBA was also detected at high levels and frequencies. Finally, 8:2 FTUCA and N-Me-FOSA were detected in every sediment sample.

Acknowledgements This study was financially supported by the National Natural Science Foundation of China (Grant No. 21577157), the Natural Science Foundation of Anhui Province, China (Grant No. 1708085MB40), and the Natural Science Foundation of the Higher Education Institutions of Anhui Province, China (Grant No. KJ2017ZD30).

\section{References}

3M, Phase-Out Plan for POSF Based Products (2000) Specialty materials Group. 3M, St. Paul

Ahrens L, Yamashita N, Yeung LWY, Taniyasu S, Horii Y, Lam PKS, Ebinghaus R (2009) Partitioning behaviour of per- and polyfluoroalkyl compounds between pore water and sediment in two sediment cores from Tokyo Bay. Japan. Environ Sci Technol 43:6969-6975

Ahrens L, Gashaw H, Sjöholm M, Gebrehiwot SG, Getahun A, Derbe E, Bishop K (2016) Poly- and perfluoroalkylated substances (pfass) in water, sediment and fish muscle tissue from lake tana, ethiopia and implications for human exposure. Chemosphere 165:352-357

Cao YX, Cao XZ, Wang H, Wan Y, Wang SL (2015) Assessment on the distribution and partitioning of perfluorinated compounds in the water and sediment of Nansi Lake, China. Environ Monit Assess 187:611

Codling G, Vogt A, Jones PD, Wang TY, Wang P, Lu YL, Corcoran M, Bonina S, Li A, Sturchio NC, Rockne KJ, Ji K, Khim JS, Naile JE, Giesy JP (2014) Histor-ical trends of inorganic and organic fluorine in sediments of Lake Michigan. Chemosphere 114:203-209

De Silva AO, Spencer C, Scott BF, Backus S, Muir DC (2011) Detection of a cyclic perfluorinated acid, perfluoroethylcyclohexane 
sulfonate, in the Great Lakes of North America. Environ Sci Technol 45(19):8060-8066

Ding B, Cheng Y, Wu J, Wu XM, Zhang HM, Luo Y, Shi XF, Wu XX, Huo JZ, Liu YY, Li Y (2017) A unique multifunctional clusterbased nano-porous terbium organic material: real-time detection of benzaldehyde, visually luminescent sensor for nitrite and selective high capacity capture of Congo Red. Dyes Pigments 146:455-466

Han C, Zhou BH, Li FS, Chen WT, Yu GM (2017) Distribution and ecological risk assessment of arsenic, mercury in the surface sediments from urban lakes of Anqing City. J Anqing Teach Coll (Natural Science Edition) 23(1):94-97,108. (In Chinese)

Hou B, Liang C, Deng H, Xie S, Chen M, Wang R (2012) Oil removing technology of residues from waste oil-based drilling fluid treated by solid-liquid separation. J Residuals Sci Technol 9(4):143-150

Hou B, Chen M, Liu M, Xiong Q (2013) Safe disposal technology of waste oil-based drilling fluids. Bull Japan Petr Inst 56(4):221-229

Hou B, Li QY, Luo Y (2015) Synthesis and mechanism of a novel organosilicone used as a selective plugging agent. J Residuals Sci Technol 12(3):149-156

Kissa E (2001) Fluorinated surfactants and repellents, 2nd edn. Marcel Dekker, New York

Lam NH, Cho CR, Lee JS, Soh HY, Lee BC, Lee JA, Tatarozako N, Sasaki K, Saito N, Iwabuchi K, Kannan K, Cho HS (2014) Perfluorinatedalkyl substances in water, sediment, plankton and fish from Korean rivers and lakes: a nationwide survey. Sci Total Environ 492(6):154-162

Lau C, Anitole K, Hodes C, Lai D (2007) Perfluoroalkyl acids: a review of monitoring and toxicological findings. Toxicol Sci 99(2):366-394

Li FS, Sun HW, Hao ZN, He N, Zhao LJ, Zhang T, Sun TH (2011) Perfluorinated compounds in Haihe river and Dagu drainage canal in Tianjin, China. Chemosphere 84:265-271

Lindstrom AB, Strynar MJ, Libelo EL (2011) Polyfluorinated compounds: past, present, and future. Environ Sci Technol 45(19):7954-7961

Liu Y, Jiang QF, Han M, Zhao XR, Guo R (2015) Contamination profiles of perfluorinated substances in surface sediments of Hongfeng Lake Basin. Res Environ Sci 28(4):517-523

Liu T, Meng FY, Cheng WB, Sun HX, Luo Y, Tang YG, Miao P (2017) Preparation of a peptide-modified electrode for capture and voltammetric determination of endotoxin. ACS Omega 2(6):2469-2473

Pan G, Zhou Q, Luan X, Fu QS (2014) Distribution of perfluorinated compounds in Lake Taihu (China): impact to human health and water standards. Sci Total Environ 487:778-784

Prevedouros K, Cousins IT, Buck RC, Korzeniowski SH (2006) Sources, fate and transport of perfluorocarboxylates. Environ Sci Technol 40:32-44
Qi YJ, Hu SB, Huo SL, Xi BD, Zhang JT, Wang XW (2015) Spatial distribution and historical deposition behaviors of perfluoroalkyl substances (PFASs) in sediments of lake chaohu, a shallow eutrophic lake in eastern china. Ecol Indic 57(4):1-10

Qi YJ, He ZS, Huo SL, Zhang JT, Xi BD, Hu SB (2017) Source apportionment of perfluoroalkyl substances in surface sediments from lakes in Jiangsu province, China: comparison of three receptor models. J Environ Sci 57(7):321-328

Shao MH, Ding GH, Zhang J, Wang L, Zhang NN, Li Y, Chen GQ, Sun YQ (2016) Occurrence and distribution of perfluoroalkyl substances (PFASs) in surface water and bottom water of the Shuangtaizi Estuary, China. Environ Pollut 216:675-681

Shi YL, Pan YY, Wang JM (2012) Distribution of perfluorinated compounds in water, sediment, biota and floating plants in Baiyangdian Lake, China. J Environ Monit 14(2):636-642

So MK, Miyake Y, Yeung WY, Ho YM, Taniyasu S, Rostkowski P, Yamashita N, Zhou BS, Shi XJ, Wang JX, Giesy JP, Yu H, Lam PKS (2007) Perfluorinated compounds in the Pearl River and Yangtze River in China. Chemosphere 68:2085-2095

Su HQ, Shi YJ, Lu YL, Wang P, Zhang M, Sweetman A, Jones K, Johnson A (2017) Home produced eggs: an important pathway of human exposure to perfluorobutanoic acid (PFBA) and perfluorooctanoic acid (PFOA) around a fluorochemical industrial park in China. Environ Int 101:1-6

Sun HW, Li FS, Zhang T. Zhang XZ, He N, Song Q, Zhang LN, Sun TH (2011) Perfluorinated compounds in surface waters and WWTPs in shenyang, china: mass flows and source analysis. Water Res 45(15):4483-4490

UNEP. The nine new POPs. 2009 [cited 2013 March 2]: http://chm. pops.int/Implementation/NewPOPs/TheNewPOPs/tabid/672/ Default.aspx\&gt

Yamashita N, Taniyasu S, Petrick G, Wei S, Gamo T, Lam PK (2008) Perfluorinated acids as novel chemical tracers of global circulation of ocean waters. Chemosphere 70(7):1247-1255

Yeung LW, De Silva AO, Loi EI, Marvin CH, Taniyasu S, Yamashita N, Mabury SA, Muir DC, Lam PK (2013) Perfluoroalkyl substances and extractable organic fluorine in surface sed-iments and cores from Lake Ontario. Environ Int 59:389-397

Zhang Y, Meng W, Guo CS, Xu J, Yu T, Fan WH, Li L (2012) Determination and partitioning behavior of perfluoroalkyl carboxylic acids and perfluorooctanesulfonate in water and sediment from Dianchi Lake, China. Chemosphere 88(11):1292-1299

Zhou Z, Liang Y, Shi Y, Xu L, Cai Y (2013) Occurrence and transport of perfluoroalkyl acids (PFAAs), including short-chain PFAAs in Tangxun Lake, China. Environ Sci Technol 47(16):9249-9257 